\title{
COMPLEXA RELAÇÃO ENTRE FORMAÇÃO CONTINUADA E AVALIAÇÃO EXTERNA NA REDE PÚBLICA DE ENSINO
}

Ana Carolina Medeiros Gatto Vieira Carvalho Adriana Varani $i^{(*)}$

\section{OS CONTEXTOS NECESSÁRIOS}

O presente trabalho tem como pretensão apresentar um aspecto de pesquisa realizada cujo objetivo foi investigar quais os sentidos atribuídos pelos professores de Língua Portuguesa da Rede Pública Estadual de um município do interior do Estado de São Paulo sobre as principais ações de Formação Continuada oferecidas pela Secretaria de Estado da Educação no período de cinco anos (2009-2014) no contexto e na relação com o Sistema de Avaliação do Rendimento Escolar do Estado de São Paulo (SARESP).

Para tanto, os dados da pesquisa foram produzidos através de três fontes: documentos relativos ao SARESP e aos programas de formação continuada da Secretaria da Educação do Estado de São Paulo, questionários respondidos por todos os professores de Língua Portuguesa da Rede Estadual de São Paulo do município em questão e entrevistas semiestruturadas com professores. É sobre os discursos dos professores nas entrevistas semiestruturadas, bem como nas respostas abertas dos questionários aplicados, sobre a complexa relação entre formação continuada e avaliação externa que centraremos a discussão nesta proposta de trabalho. As entrevistas semiestruturadas foram realizadas com quatro professores de Língua Portuguesa, com mais de 10 anos de exercício profissional, que participaram das ações de formação continuada pela Secretaria da Educação no período pesquisado (2009-2014) e que atuavam nas escolas da Rede Estadual de Ensino no município estudado. O campo da Língua Portuguesa foi escolhido, pois é uma das áreas avaliadas pelo SARESP, com grande ênfase nos processos de formação continuada.

A partir do discurso dos professores é possível adentrar o cotidiano de diversas escolas públicas da rede estadual de ensino do município em questão, com a finalidade de compreender como esses professores constroem ou reconstroem as políticas públicas com as quais convivem e notar o "fundo noturno da atividade social" (CERTEAU, 1990). A intenção do estudo não foi olhar apenas para o que os professores dizem, mas também de observar o que não dizem. Como afirma

\footnotetext{
${ }^{(*)}$ Ana Carolina M.G. Carvalho. Mestre em Educação, pela Universidade de São Carlos. Pedagoga na Instituto Federal de São Paulo.

Adriana Varani. Professora na Universidade Estadual de Campinas.
} 
Geraldi et al. (2015, p.20) "é fundamental que os saberes da experiência sejam resgatados e postos em diálogo com o conhecimento científico".

Desta forma, contribuímos com o cenário científico, na medida em que encontramos na escola, e principalmente nos professores, que junto com os alunos protagonizam as práticas pedagógicas, sujeitos que têm o que dizer, que elaboram suas experiências e as revalidam no cotidiano escolar.

A dimensão subjetiva abrange a história de cada sujeito, manifesta no cotidiano escolar, por suas formas concretas de representação social, por meio das quais ele age, posiciona-se, aliena-se e comunica-se. Daí a importância de estudar o indivíduo numa dada situação socializadora, isto é, verificar como se concretizam, no dia-a-dia os valores, sentidos e significados produzidos pelos sujeitos. (ANDRÉ, 2008, p. 142).

A opção metodológica foi trilhada a partir das inquietações do problema da pesquisa. A cada nova descoberta foi necessário um novo tipo de análise, uma nova investigação. Na análise não foram ignorados os aspectos subjetivos, pois há inúmeras variáveis que se estabelecem na relação pesquisada. Consideramos que o tema discutido nesta pesquisa não é passível de ser lido linearmente, devido às relações complexas e contraditórias que são estabelecidas.

André (2008, p. 140) afirma que "a complexidade do objeto: escola pública fundamental é extremamente complexa e, para entendê-la, há que se recorrer a múltiplos referenciais, explorar muitos ângulos, utilizar uma multiplicidade de instrumentos e técnicas”.

Havia uma relação onde nasceu a pesquisa, a questão surgiu a partir da atividade desenvolvida profissionalmente por uma das autoras, que atuou como Professora Coordenadora do Núcleo Pedagógico de Língua Portuguesa (PCNP) ${ }^{1}$, responsável pela formação dos professores com aos quais esta pesquisa foi realizada. Como a pesquisa se desenvolveu no campo de atuação profissional, além da coleta de dados que foi planejada através dos questionários, entrevistas e análise documental, a própria atuação profissional trazia à tona a complexidade da temática pesquisa, nas situações, textos e discursos que circulavam no cotidiano que foram alimentando as leituras e ampliando as discussões da pesquisa.

\footnotetext{
${ }^{1}$ Docentes designados para ocupar o posto de trabalho de Professor Coordenador, cujas funções estão definidas pelo Decreto 57.141/11, artigo 73. Disponível em :< https://www.al.sp.gov.br/repositorio/legislacao/decreto/2011/decreto57141-18.07.2011.html> Acesso em 20 jun. 2018.
} 
$\mathrm{Na}$ tentativa de nos ater a complexidade da questão pesquisada também foram revisitados o inventário $^{2}$ de pesquisa e as "memórias do cotidiano", narrativas do dia a dia registradas no diário de campo, lugar da circulação do texto não oficial que possibilitou um novo olhar sobre o que vemos todos os dias, mas que quando nos detivemos pudemos perceber novos sentidos.

Embora a pesquisa tenha sido realizada com um grupo de professores de um município do estado de São Paulo, não deixa de se articular de maneira contextual. É das questões do cotidiano que partimos para discutir as questões gerais em educação.

Este tipo de pesquisa permite documentar o não documentado, isto é, desvelar os encontros e desencontros que permeiam o dia-a-dia da prática escolar, descrever as ações e representações dos seus atores sociais, reconstruir sua linguagem, suas formas de comunicação e os significados que são criados e recriados no cotidiano do seu fazer pedagógico. (ANDRÉ, 2008, p. 141).

Para discussão apresentada na pesquisa sobre os "sentidos" elaborados pelos professores nas respostas às questões abertas do questionário e às entrevistas, nos apoiamos na Teoria Histórico Cultural de Lev Seminovich Vygotksy.

Os sentidos atribuídos pelos sujeitos para determinadas ações e situações são determinados pela posição social ocupada pelos sujeitos. Embora, o conceito ou o objeto sejam os mesmos, os sentidos atribuídos são diferentes, visto que cada sujeito os elabora a partir das suas experiências e a relação estabelecida com o conceito ou objeto.

Para Vygotsky (2000, p. 465):

o sentido de uma palavra é a soma de todos os fatos psicológicos que ela desperta em nossa consciência. Assim, o sentido é sempre uma formação dinâmica, fluida, complexa, que tem várias zonas de estabilidade variada. O significado é apenas uma dessas zonas do sentido que a palavra adquire no contexto de algum discurso e, ademais, uma zona mais estável, uniforme e exata.

Nesta pesquisa tratamos de temas dos quais compartilhamos os significados, assim interessa-nos observar os diferentes sentidos atribuídos, como cada professor que participou da pesquisa interpreta o mundo e as experiências e vive.

\footnotetext{
2 "Inventário" é o termo usado pelos pesquisadores Prado e Morais (2011) como possibilidade de organização dos dados de uma pesquisa. PRADO, G. V. T. e MORAIS, J. F. S. Inventário - organizando os achados de uma pesquisa. Revista EntreVer, Florianópolis, v. 01, n.01, p. 137-154, 2011.
} 


\section{AS RELAÇÕES LIDAS NOS DISCURSOS CONSTRUÍDOS}

Neste estudo, focalizamos a questão pesquisada no contexto do Estado de São Paulo, cuja política educacional tem sido fortemente influenciada por países desenvolvidos, cujos interesses passam pela interferência na política de países em desenvolvimento como o Brasil, com a finalidade de ter as melhores escolas possíveis, desconsiderando o contexto onde elas estão inseridas, os recursos disponíveis e a capacidade local.

No contexto neoliberal, as melhores escolas possíveis, são aquelas que alcançam níveis de qualidade que são observados nos resultados do rendimento escolar, medidos através das avaliações externas, que tem em suas matrizes de avaliação: leitura e matemática. Como afirma Torres (2009, p. 134), a qualidade é medida pelo "próprio equipamento escolar, sem questionar a validade, o sentido e os métodos de ensino daquilo que se ensina"

Dos dados construídos, muitos discursos foram problematizados no texto final da pesquisa. Neste momento faremos um recorte dos discursos e como eles nos remetem a complexidade de sentidos perpassados no cotidiano.

A seguir apresentamos os dados das entrevistas em que os professores indicam que há relação entre a avaliação externa e os cursos de formação continuada quando os estes focam os conteúdos, as competências e habilidades da matriz de Referência da Avaliação - SARESP. Uma das entrevistadas, professora Adélia, afirma que existe relação entre a formação continuada da rede e o SARESP.

O SARESP ele traz pra gente a questão do que se cobra dos alunos, o que o aluno deve aprender realmente, então quando a gente estuda as habilidades que devem ser desenvolvidas ou quando a gente estuda porque determinado conteúdo envolve aquela habilidade. Levam nosso olhar para esse sentido, de ver assim. Muitas vezes a gente trabalha o conteúdo de forma mecânica e o SARESP trabalha aquele determinado texto, ele desenvolve estas e estas e estas habilidades, neste sentido, a formação continuada contribuiu muito. A gente passa a ter um olhar diferente do que trabalhar em sala de aula. E assim, nos leva também a conhecer quais as habilidades que os alunos têm que desenvolver em determinada série. (Professora Adélia)

Ela nos leva a pensar atentamente sobre como passou a prestar atenção na habilidade que nunca havia se dado conta, graças aos cursos que se baseiam no SARESP.

Ao se referir à relação entre a formação continuada proposta pela rede e os resultados do SARESP, ela afirma. 
A formação continuada ela está voltada para o desenvolvimento das habilidades, até que se chega até a competência leitora, competência escritora. A formação continuada, formação do SARESP, viabiliza isso, leva a gente a ver essa questão da habilidade a ser trabalhada e o que realmente se desenvolve no aluno, eu acredito que sim. (Professora. Adélia).

Na continuidade, percebe-se que a professora assume que se são trabalhadas as habilidades e suas formas de desenvolvimento, por consequência, há influência no resultado do SARESP.

No que se refere ao questionamento se suas práticas foram alteradas para a melhoria dos resultados, a professora afirma

Muitos cursos trazem essas habilidades [...] o SARESP traz com base no Currículo exatamente o que é necessário, aquilo que o aluno precisa saber. Cursos que a gente faz trazem essas habilidades, quando trabalham a produção textual, trabalham leitura, as estratégias de leitura, as informações que a gente deve incentivar os alunos, não só incentivar, mas desenvolver nos alunos: a percepção do texto, a recepção do texto. Então acaba contribuindo bastante para isso. (Professora Adélia)

Ao analisarmos os dados das entrevistas percebemos que há a explicitação, pelos professores, da relação entre os cursos de formação continuada oferecidos pela Secretaria da Educação e a avaliação externa. Ao reler o discurso da professora Adélia encontramos a afirmação que o conhecimento que o aluno precisa saber está definido no SARESP, ou seja, há uma concordância que o SARESP define o que se deve saber na escola. Isto nos leva a refletir sobre como a avaliação tem centralidade no processo do trabalho

E assim fica evidente que o conteúdo de muitos cursos está ancorado nas discussões sobre as habilidades e competências constantes da Matriz de Avaliação e do Currículo do Estado de São Paulo. É a Matriz de Referência para avaliação - SARESP ${ }^{3}$, que indica quais conteúdos, habilidades e competências serão testadas nas provas.

De acordo com o documento "Matrizes de Referência para avaliação - SARESP: documento básico" (2009, p. 11), esta matriz tem "seu poder de sinalização das estruturas básicas de conhecimentos a serem construídas por crianças e jovens por meio dos diferentes componentes curriculares em cada etapa da escolaridade básica." A matriz é elaborada a partir do Currículo Oficial do Estado de São Paulo. Percebe-se também que houve uma mudança de olhar do professor

\footnotetext{
3 Disponível em: http://saresp.fde.sp.gov.br/2009/pdf/Saresp2008 MatrizRefAvaliacao_DocBasico_ Completo.pdf Acesso em 20 jul. 2018.
} 
para o conteúdo. E que ele acaba por mostrar ao professor o que é requerido na prova e a partir daí trabalhar a habilidade requerida com mais competência.

Sabemos que o processo de ensino e aprendizagem escolar não pode estar contido em uma prova de múltipla escolha e que ela pode apresentar apenas um "recorte" de tudo o que é aprendido e vivenciado no ambiente escolar. Geraldi (2010, p. 97) afirma que o "vivido não é interrogado", desta forma, a qualidade da experiência escolar fica reduzida ao resultado de um teste padronizado. Para Esteban (2005, p.14) a prática do exame

reduz a riqueza e a complexidade dos processos de aprendizagem e de ensino, das relações sociais nas quais as relações pedagógicas se constituem e dos sujeitos que aprendem e que ensinam, como a materialização da concepção positivista do conhecimento.

Os testes padronizados ${ }^{4}$ das provas do SARESP medem o desempenho dos alunos e isso faz com que a centralidade da prática pedagógica seja deslocada do seu processo, para os resultados. Quando os resultados são mais importantes, retomamos a lógica da avaliação em larga escala e inicia-se um processo de trabalho para alcançar os bons resultados. E uma das formas de alcançar este "bom resultado" e inverter a lógica do processo ensino aprendizagem, é enfatizar habilidades como fim de aprendizagem. Barriga (1999) diz de uma inversão do papel do exame na construção do trabalho pedagógico. A avaliação que poderia ser um elemento para mediar o aprendizado, é um elemento usado como fim do aprendizado. Esquece-se todo o processo que tem no entrelugar, nas relações ensino aprendizagem e nas manifestações do sujeito que vão para além do conteúdo.

O pesquisador Luiz Carlos de Freitas, chama a redução do ensino às disciplinas testadas na avaliação externa de estreitamento curricular produzido pelos 'standards' centrados em leitura e matemática. Freitas (2011, p. 12) adverte:

a consequência é o estreitamento curricular focado nas disciplinas testadas e o esquecimento das demais áreas de formação do jovem, em nome de uma promessa futura: domine o básico e, no futuro, você poderá avançar para outros patamares de formação. Todos sabemos que a juventude mais pobre depende fundamentalmente da escola para aprender, e se for limitada a sua passagem pela escola as habilidades básicas, nisso se resumira sua formação.

\footnotetext{
4 Há no Brasil o "Movimento contra testes de alto impacto na Educação", cujo objetivo é alertar educadores, pais, políticos, juristas, Ministério Público, estudantes, diretores e a sociedade em geral sobre os riscos já constatados em outros países, devidos ao uso inadequado dos processos de avaliação baseados nestes testes. Disponível em: <https://sites.google.com/site/movimentocontratestes/home> Acesso em 20 jul. 2018
} 
Ainda segundo Freitas (2011, p.14) além desta primeira redução que é o estreitamento curricular que se efetiva através da concentração dos esforços educacionais em apenas duas disciplinas testadas nas avaliações externas: português e matemática, há uma segunda redução quando "escolhemos dentro do conhecimento de português quais competências e habilidades" devem ser estudadas.

Assim, a formação continuada que deveria abranger os diferentes temas da Língua Portuguesa passa também pelo estreitamento curricular, quando discute apenas as habilidades e competências da avaliação.

De forma mais evidente nas entrevistas, os professores indiciam que a relação entre formação e avaliação é positiva, percepção que pode advir dos processos de responsabilização nos quais estão inseridos.

Nas respostas às entrevistas, vemos os posicionamentos contextualmente, o que nos leva a outras leituras possíveis. Para professora Lygia também perguntamos se ela percebe alguma relação entre os cursos de formação continuada e a avaliação externa-SARESP:

Porque se eles estão pedindo as competências e habilidades, naqueles eixos, pensando tudo aquilo, os cursos oferecidos também vão nos capacitar para poder oferecer isso com propriedade para os alunos, para que eles consigam pegar a prova e consigam observar aquilo que a gente vai trabalhar em sala de aula. A gente só consegue enxergar isso com as formações, que pode ter um leque de coisas, um mundo de coisas, que pode estar adaptando dentro do currículo, e que vai ajudá-los no SARESP. (Professora Lygia).

A professora entrevistada indica a lógica necessária para atender ao requerido pela avaliação externa. Neste sentido aparentemente o que está compreendido pela professora é que os adolescentes devem mesmo dominar estas habilidades. Se a formação acentua tais habilidades e o SARESP também, logo o trabalho pedagógico escolar deve ser visto com sua centralidade no desenvolvimento da Matriz.

Estes discursos nos levam a compreender que o movimento do trabalho em aula centra-se no necessário resultado, indicado pelas políticas de governo. E mais que isto, demonstra como a lógica da relação direta e estreita entre avaliação externa e formação está nas concepções circulantes dos professores nas escolas. É a avaliação como determinante do trabalho escolar. Freitas et al. (2014) nos mostram a dimensão da avaliação como centralidade do trabalho pedagógico, quando se restringia a avaliação da aprendizagem. Neste momento atual, ela se configura com a roupagem da avaliação externa. 
O discurso da professora Clarice, nos evidencia as relações entre formação, currículo e avaliação externa, ao ser questionada se acham que o resultado do SARESP é uma avaliação dos cursos de formação continuada ofertados pela rede.

SARESP, currículo e formação é tudo uma coisa, é uma linha de raciocínio só.

Ninguém precisa ser gênio. Se você ler o que é o currículo, formação continuada, você vai entender porque a prova do SARESP é feita daquele modelo, é a mesma linha de raciocínio, eu não consigo dividir, uma parte, muita gente não entendeu, mas é só uma parte. Eu acredito nisso, não sei se eu estou errada. (Professora Clarice)

Clarice aponta a dimensão com um olhar mais crítico, quando aponta a estreita relação entre currículo, avaliação externa e formação, afirmando que o "SARESP, o Currículo e a formação é tudo uma coisa só, é uma linha de raciocínio só”. Uma tríade, já anunciada por Arroyo, que controla os processos educativos com o mesmo movimento para a política de resultados.

O que se avalia e como se avalia está condicionado pelas competências, habilidades, conhecimentos que o currículo privilegia ou secundariza. Os valores e as lógicas de avaliação reproduzem os valores, lógicas e hierarquias que selecionam, organizam os conhecimentos nos currículos. Por sua vez, o que se privilegia nas avaliações escolares e nacionais determina as competências e conhecimentos privilegiados ou secundarizados no currículo. (ARROYO, 2007, p. 13).

Apesar de não nos determos neste artigo nos dados produzidos nos questionários, vale retomar uma discussão proveniente que nos chamou a atenção. Na observação dos dados pudemos perceber que os professores têm dificuldade em expor sua implicação no processo de mudança dos resultados da avaliação externa, como é possível observar em: "Quando o professor trabalha o que aprendeu no curso", "Levam o professor" ou "Quando o professor é capacitado". A utilização da terceira pessoa e de generalizações como forma de fuga à resposta é um recurso para sua não implicação com a questão, ou ainda podem indicar que os professores acreditem que a formação continuada não contribui para melhoria dos resultados da avaliação externa.

Algumas respostas extrapolam as questões da avaliação externa e há indícios que os professores percebem que a formação não basta para mudança nos resultados: "As avaliações externas não dependem apenas das práticas dos professores, mas também da 'boa vontade' dos alunos" e "Pela conscientização docente". Nestes dois trechos podemos retomar algumas considerações sobre avaliação que já foram feitas: os professores percebem que a avaliação é tomada como um fim em si só e que é desconsiderado o contexto em que está inserida.

Esta reflexão está pautada em dois depoimentos de professores ao serem questionados sobre se acham que a participação nos cursos influencia os resultados do SARESP. 
Sim, tem que influenciar. Porque quando a gente está aprendendo, se você vai mudar a sua prática, vai repensar naquilo que você está fazendo, você vai melhorar, você vai trazer coisas que tem sentido para eles e que venha depois, a cair do SARESP. (Professora Lygia).

Os cursos, eles, como posso dizer? Os cursos são direcionados às novas estratégias, o SARESP nada mais é do que a avaliação de todo um processo que você teve em sala de aula de um ano ou mais.

[...] Você que vai estar direcionando o aluno, a partir do momento em que você é abastecido com novas estratégias que o curso proporciona, você passa para os alunos de uma nova maneira, e essa nova maneira pode fazer com que eles apresentem bons resultados no dia a dia, consequentemente em uma avaliação como o SARESP, eles vão bem. (Professor Carlos).

Ao analisarmos as respostas dadas pelos professores no questionário e nas entrevistas percebemos que ainda há uma percepção que a melhoria do resultado das avaliações externas se daria apenas com a mudança da metodologia do professor. Essa percepção reduz a avaliação externa ao que acontece em sala de aula, e acaba por responsabilizar o professor individualmente pelos resultados obtidos, desconsiderando o contexto onde a avaliação se desenvolveu.

A esse processo de responsabilização e individualização dos resultados Ball (2001, p. 109) chama de performatividade:

A performatividade é uma cultura ou um sistema de 'terror' que emprega julgamentos, comparações e exposição como forma de controle, atrição e mudança. O desempenho (de sujeitos individuais ou organizações) funciona como medida de produtividade ou resultado, ou exposição de 'qualidade', ou 'momentos' de produção ou inspeção.

A Professora Clarice demonstra os sentidos que atribui a individualização da culpa “(...)o que aconteceu aí, falhei?”

A performatividade atinge profundamente a percepção do eu e de nosso próprio valor.

Coloca em pauta uma dimensão emocional, apesar da aparência da racionalidade e objetividade. Assim, nossas respostas ao fluxo de informações a respeito do desempenho podem engendrar nos indivíduos sentimentos de orgulho, culpa, vergonha e inveja. (BALL, 2005, p. 550)

Ao contrário da Professora Clarice, Professor Carlos se sente orgulhoso com o trabalho desenvolvido, indicando um outro sentimento produzido pela performatividade, quando afirma "referente a 2014 teve um resultado ótimo tanto do ensino fundamental quanto do ensino médio e isso mostra que a gente tá no caminho certo, tá fazendo um bom trabalho". (Professor Carlos) 
A maioria dos professores experimenta esses sentimentos tão contraditórios durante todo seu percurso profissional e isso os leva a acreditar que são exclusivamente responsáveis pelos resultados, reforçando a culpabilização docente:

Teve ano em que eu peguei salas, por exemplo, nono ano, que nossa! Depois eles arrasaram no SARESP. Delícia, né?! E, às vezes, quando você forma aquela turma que não alcança, você fala: Ai meu Deus! O que fiz de errado, que a outra deu tão certo, e com essa não deu nada certo? O que será? (Professora Lygia).

Desta forma, vemos como a avaliação externa influencia o cotidiano na escola e seja para superação do sentimento de culpa ou para manutenção do sentimento de orgulho.

Sobre a formação os professores entrevistados indicam que ela não deve ser apenas voltada para o SARESP, mas para as práticas em sala de aula e para dificuldades apresentadas pelos professores que, na maioria das vezes, são ignoradas. Segundo Lüdke e Sordi (2009)

Perde-se a chance de se promover uma aproximação do coletivo da escola para estabelecer uma leitura circunstanciada dos dados, produtora de significados e subsidiadora de decisões internas que levem em conta os saberes dos atores locais e as informações geradas fora da escola, que poderiam dialogar. (p. 320).

Perde-se a chance também de ampliar a discussão do trabalho da escola para além da produção de números, o que o professor Carlos faz questão de frisar ao encerrar sua entrevista.

A formação continuada, o SARESP, enfim, eu acho que nossa profissão é muito gratificante, você vê que o aluno espera muito de você e que se ele consegue, você já ganhou ali o ano. Excelente isso. E ao mesmo tempo é uma profissão muito cobrada e às vezes quem cobra está muito distante da realidade. Às vezes, o sistema cobra demais, vê números e a gente não trabalha com números, trabalha com pessoas. Só quem vê pessoa e não vê números somos nós que estamos na sala de aula. (Professor Carlos).

Para o professor Carlos, o SARESP é a consequência do trabalho desenvolvido em sala de aula durante o ano. No trecho da entrevista em questão, o professor Carlos indicia mais uma vez a "responsabilização docente" quando se refere às cobranças recebidas e que elas vêm, muitas vezes, de pessoas que desconhecem a realidade escolar.

Clarice faz outra associação sobre como deve ser conduzida a formação continuada no contexto da avaliação externa.

$\mathrm{Eu}$ acho que (formações) voltada para uma avaliação não é o termo. Eu acho que ela deve ser voltada às práticas reais em sala de aula. $\mathrm{Na}$ verdade, se você for seguir o currículo, o currículo vai te levar para o SARESP e vice-versa. Não é o SARESP, mas 
acho que todas as práticas e as dificuldades. Eu acho que as dificuldades do professor em sala de aula são muito ignoradas. Eu acho que o professor, por exemplo, nós temos professores na escola que participam das formações. E temos professores que não participam, às vezes participam e não conseguem desempenhar um papel de professor, nem de comandante da sala de aula. E não existe nada e nem ninguém que faça com que aquela pessoa estude, com que aquela pessoa dê um norte, está ali por estar. Eu acho que é aí que nós temos que ver hoje a formação. (Professora Clarice).

Para além do fim avaliação externa, a professora acredita que a formação deva estar voltada para as práticas reais em sala de aula. Parece-nos que ela distingue o currículo daquela que ela chama de práticas e das dificuldades dos professores em sala de aula. Uma interpretação possível é que as práticas a que se remete a professora estão no campo dos aspectos metodológicos, da suposta condução técnica do que é conhecimento a ser transmitido. Para ela o currículo, se seguido, já levaria o professor ao SARESP. O que não o leva é a condução do trabalho em aula. E aí está a necessidade da formação.

Os professores entrevistados indicam também que a maioria dos cursos estudam os conteúdos que envolvem as competências e habilidades do SARESP. Entretanto, na perspectiva dos entrevistados seria importante que os cursos não se centrassem apenas no SARESP, mas na dificuldade dos professores e nas práticas de sala de aula.

Os dados coletados nos encaminham para a reflexão que a formação continuada mais adequada do ponto de vista dos professores seria aquela que colocasse em circulação os conhecimentos que os professores construíram sobre a própria prática docente, gerando um espaço de diálogo e reflexões que possibilitem a construção de encaminhamentos e soluções para os desafios encontrados no cotidiano da sala de aula, como nos indica Nóvoa (1992, p. 28):

É preciso trabalhar no sentido da diversificação dos modelos e das práticas de formação, instituindo novas relações dos professores com o saber pedagógico e científico. A formação passa pela experimentação, pela inovação, pelo ensaio de novos modos de trabalho pedagógico. E por uma reflexão crítica de sua utilização.

Uma informação contextual importante para continuarmos o debate, para além de como os professores reconhecem esta relação diz respeito ao aumento quantitativo de formações nas duas áreas avaliadas no SARESP. 
Tabela 1. Número de Orientações Técnicas/Cursos oferecidos pela Diretoria de Ensino pesquisada por disciplina no ano de 2013/2014

\begin{tabular}{l|l|l}
\multicolumn{2}{c}{ Número de formações } \\
\hline Disciplina & 2013 & 2014 \\
\hline Matemática & 34 & 26 \\
\hline Língua Portuguesa & 29 & 36 \\
\hline Arte & 9 & 2 \\
\hline Inglês & 6 & 2 \\
\hline Ciências & 5 & 3 \\
\hline Educação Física & 5 & 2 \\
\hline Física & 4 & 1 \\
\hline História & 4 & 1 \\
\hline Biologia & 4 & 0 \\
\hline Filosofia & 3 & 0 \\
\hline Geografia & 2 & 1 \\
\hline Química & 2 & 1 \\
\hline Sociologia & 1 & 1 \\
\hline
\end{tabular}

Fonte: Cadastro de Ações de Formação - Rede do Saber/SEE (2015).

O desejo de melhoria dos resultados e da qualidade da educação é medido através das avaliações externas. Assim, mesmo que de forma implícita, há uma relação entre a implementação dos cursos com vistas à melhoria dos índices das avaliações externas.

Nota-se que a intensificação dos processos de formação, traduzidos fortemente no número de formações oferecidas em Português e Matemática geralmente, decorre dos índices alcançados na avaliação. Esses projetos parecem ter relação com a política de criação da eficiência escolar, conforme Ball (2005, p. 548).

A eficácia prevalece sobre a ética; a ordem sobre a ambivalência. Essa mudança na consciência e na identidade do professor apoia-se e se ramifica pela introdução, na preparação do professor, de formas novas de treinamento não-intelectualizado, baseado na competência.

Os resultados da avaliação externa por escola e por turmas são analisados e orientam o trabalho escolar, definindo habilidades, conteúdos e competências a serem ensinados aos alunos e aprendidos pelos professores para que sejam mais "eficientes" em seu trabalho. Assim, "pode-se afirmar que o SARESP vem se fazendo presente gradualmente, influenciado práticas, definindo

\footnotetext{
${ }^{5}$ Dados referentes à planilha de consolidação dos dados do Cadastro de Ações de Formação (Cadformação) que registra as ações de formação continuada centralizadas e descentralizadas de modo presencial, em serviço ou por meio de mídias interativas. Disponível em: 〈http://www.rededosaber.sp.gov.br/portais/Default.aspx?tabid=2813> Acesso em: 20 jul. 2018.
} 
metas, estabelecendo rumos, orientando o trabalho pedagógico". (BONAMINO, 2012, p. 385). É o que nos indica também os discursos dos professores acima construídos.

A formação de professores no contexto da avaliação externa - SARESP, também nos possibilita observar os processos de responsabilização dos sujeitos. A Secretaria da Educação oferece um número grande de ações de formação nas disciplinas testadas pelo SARESP, com a finalidade de melhorar os resultados, como vimos na análise dos documentos referentes aos cursos.

Desta forma, os professores não podem alegar que não tem formação para melhorar o desempenho dos alunos na avaliação externa, como afirma a Professora Clarice:

Quando a gente vai pra formação vocês mostram pra gente determinadas, muitas opções de trabalho, né? Não imposições, mas opções. E gentilmente (risos) dizem pra gente, olha esse caminho aqui é o mais curto e mais fácil, então, quem tem ouvidos, ouve, simples assim. Não é?

Essa afirmação da Professora Clarice nos leva a refletir sobre o sentido que ela atribuiu às formações oferecidas: "E gentilmente (risos) dizem pra gente, olha esse caminho aqui é o mais curto e mais fácil, então, quem tem ouvidos, ouve". Isso indica que ela adere aos processos de formação e aos conteúdos que são proporcionados para não ser responsabilizada posteriormente.

\section{ALGUMAS PALAVRAS FINAIS}

No campo da relação entre avaliação externa e formação continuada, há algumas sínteses provisórias dos sentidos produzidos para a relação formação continuada e avaliação externa. A primeira é o quanto pelo discurso apreendido, há uma visão de naturalização do processo desta relação, quando professores aceitam que o conteúdo será melhor trabalhado, uma vez que haverá formação e que na lógica, os alunos aprenderão melhor. Há uma aceitação do processo de avaliação externa como indicador de que há realmente aprendizagem. Além de não questionarem o fato de que estas formações colaboram com a restrição do que ensinam, uma vez que não estão voltadas para demais conteúdos importantes, mas que não são cobrados nos processos de avaliação.

Outra questão é a percepção pelos professores do que foi constatado em termos numéricos também, há uma ampliação substancial de cursos de formação nas áreas avaliadas pelo SARESP Matemática e Língua Portuguesa - em detrimento de outras áreas de conhecimento. Os professores, neste caso de Língua Portuguesa, afirmam que são demandados com frequência para realização de cursos de formação. 
Esta trama da relação entre formação continuada e avaliação externa reafirma como síntese do processo, como esta relação atende à questão dos processos de eficiência escolar a que Ball se refere.

Não poderíamos deixar de mencionar, pois nos salta aos olhos, como as discussões apresentadas nos levam a refletir sobre a relevância da avaliação no processo educativo. A avaliação sempre vai ocupar um papel central no processo educativo, e é exatamente pela centralidade que ocupa na escola/sociedade, que nos permite, contraditoriamente, nos apropriemos desta centralidade para outros fins. (FREITAS, 2014, p. 24).

A avaliação, quando compreendida como diagnóstico do que foi ou não aprendido pelos alunos, como indicação para mudança de rumos para garantir que todos aprendam, respeitando a individualidade, nos leva a resgatar o principal objetivo da escola: a formação dos alunos. Assim a avaliação é colocada em seu devido lugar, como nos adverte Álvarez Méndez (2002, p.35):

Nem tudo o que é ensinado deve transformar-se automaticamente em objeto de avaliação; nem tudo que é aprendido é avaliável, nem o é no mesmo sentido, nem tem o mesmo valor. Felizmente, os alunos aprendem mais do que os professores costumam avaliar.

Mesmo com as dificuldades impostas, com a desconsideração dos contextos onde os professores desenvolvem suas atividades, com as políticas de responsabilização e de eficiência escolar, nos arriscamos a considerar, apropriando-nos da afirmação de Álvarez Méndez, que felizmente os professores ensinam mais do que as avaliações externas costumam avaliar. 


\section{REFERÊNCIAS}

ÁLVAREZ MÉNDEZ, J. M. Avaliar para conhecer: examinar para excluir. Porto Alegre: Artmed, 2002.

ANDRÉ, M. D. Pesquisa sobre a escola e pesquisas no cotidiano da escola. Eccos - Revista Científica, São Paulo, v. 10, p. 113-145, Especial 2008.

ARROYO, M. G. Indagações sobre Currículo: Direitos e o Currículo. Brasília: Ministério da Educação, Secretaria da Educação Básica, 2007, 52p.

BARRIGA, A.D. Uma polêmica em relação ao exame. In: ESTEBAN, M. T. (Org). Avaliação: uma prática em busca de novos sentidos. Rio de Janeiro. DP\&A, 1999. p. 83-99.

BONAMINO, A. S. Três gerações de avaliação da educação básica no Brasil: interfaces com o currículo da/na escola. Educação e Pesquisa, São Paulo, v. 38, n. 2, p. 373-388, abr./jun. 2012.

BALL, S. J. Diretrizes Políticas Globais e Relações Políticas Locais em Educação. Currículo sem fronteira, v. 1, n. 2, p. 99-116, jul./dez. 2001.

BALL, S.J. Profissionalismo, gerencialismo e performatividade. Cadernos de pesquisa, São Paulo, v. 35, p. 539-564, set./dez. 2005.

CERTEAU, M. A invenção do cotidiano. Rio de Janeiro: Vozes, 1990.

ESTEBAN, M. T. (Org.). Escola, Currículo e Avaliação. 2. ed. São Paulo: Cortez, 2005.

FREITAS, L.C. Responsabilização, meritocracia e privatização: conseguiremos escapar do neotecnicismo? Caderno Cedes, Campinas, p. 1-35, fev. 2011.

FREITAS, L. C. et al. Avaliação Educacional: caminhando na contramão. 7. ed. Petrópolis: Vozes, 2014.

GERALDI, J. W.; LIMA, M. E.; GERALDI, C. M. O trabalho com narrativas na investigação em educação. Educação em Revista, Belo Horizonte, v. 31, n. 01, p. 17-44, Jan.-Mar. 2015.

NOVOA, A. Formação de professores e profissão docente. Os professores e sua formação. Lisboa: Dom Quixote, 1992. Cap. 1, p. 15-33.

PRADO, G. V.T.; MORAIS, J. F.S. Inventário - organizando os achados de uma pesquisa. Revista EntreVer, Florianópolis, v. 01, n. 01, p. 137-154, 2011.

SORDI, M.R.; LÜDKE, M. Da avaliação da aprendizagem à avaliação institucional: aprendizagens necessárias. Revista da Avaliação da Educação Superior, Sorocaba, v. 14, p. 313-336, jul. 2009.

TORRES, R.M. Melhorar a qualidade da educação básica? As estratégias do Banco Mundial. In: TOMASSI, L.E. O Banco Mundial e as políticas educacionais. 6. ed. São Paulo: Cortez, 2009. Cap. 4, p. 126-189.

VYGOSTKY, L.S. A construção do pensamento e da linguagem. São Paulo: Martins Fontes, 2000. 


\section{RESUMO}

Apresentamos uma reflexão sobre sentidos produzidos da relação entre formação continuada da rede pública do Estado de São Paulo e avaliação externa a partir de discursos de professores. A metodologia utilizada foi referenciada nos estudos do cotidiano e na abordagem de recuperação dos sentidos em Vygotsky. A reflexão dos dados inferi que a relação em questão tem prejudicado essas ações ao longo dos anos, por enfatizar as disciplinas cobradas no SARESP num processo de performatividade, pautando-se em Ball. Os discursos dos professores mostram a complexidade dos posicionamentos no cotidiano escolar, e levam a refletir sobre as contradições existentes, entre o desejo de ter autonomia do trabalho e a aceitação da necessidade de avaliações regulatórias e responsabilizadoras.

Palavras-chave: Avaliação Externa, Formação Continuada, Políticas de Formação.

\section{THE COMPLEX RELATIONSHIP BETWEEN CONTINUOUS TRAINING AND EXTERNAL EVALUATION IN THE PUBLIC EDUCATION NETWORK}

\section{ABSTRACT}

We present a reflection on the meanings produced by the relationship between continuing education in the public network of the State of São Paulo and external evaluation based on teachers' discourses. The methodology used was referenced in the studies of the daily life and the approach of recovery of the senses in Vygotsky. The reflection of the data inferred that the relationship in question has impaired these actions over the years, for emphasizing the disciplines collected in the SARESP in a process of performativity, being based on Ball. The teachers' discourses show the complexity of the positions in the daily school life, and lead to reflect on the existing contradictions, between the desire to have autonomy of work and the acceptance of the need for regulatory and accountability assessments.

Keywords: External Evaluation, Continuing Education, Policies of teacher education

\section{LA COMPLEJA RELACIÓN ENTRE FORMACIÓN CONTINUADA Y EVALUACIÓN EXTERNA EN LA RED PÚBLICA DE ENSEÑANZA}

\section{RESUMEN}

Presentamos una reflexión sobre sentidos producidos de la relación entre formación continuada de la red pública del Estado de São Paulo y evaluación externa a partir de discursos de profesores. La metodología utilizada fue referenciada en los estudios del cotidiano y en el abordaje de recuperación de los sentidos en Vygotsky. La reflexión de los datos infería que la relación en cuestión ha perjudicado esas acciones a lo largo de los años, por enfatizar las disciplinas cobradas en el SARESP en un proceso de performatividad, pautándose en Ball. Los discursos de los profesores muestran la complejidad de los posicionamientos en el cotidiano escolar, y llevan a reflexionar sobre las contradicciones existentes, entre el deseo de tener autonomía del trabajo y la aceptación de la necesidad de evaluaciones regulatorias y responsabilizadoras.

Palabras clave: Evaluación externa, formación continua, políticas de formación de profesorado. 